\title{
Extraction of Energy from Earth's Womb
}

\author{
Rajapraveen.k.n ${ }^{1}$, Dr. N. K.Prasanna kumari ${ }^{2}$ \\ ${ }^{I}$ (M.tech/Department of computer science \& engineering, sset/Sam Higginbottom Institute of Agriculture, \\ Technology \& Sciences-deemed University, India, ${ }^{2}$ (NIMH, Nagpur)
}

\begin{abstract}
Now at present we all depended upon renewable sources like wind energy, solar energy etc. To stop fossil fuels consumption and control the pollution in atmosphere. Here we are moving a step forward to retrieve energy from earth's womb. By using the heat inside the earth we can generate electricity for signifying use. We know that heat is defined as energy transferred to the system by thermal interactions.

Keywords: energy in earth, extraction of energy from earth, energy in earth's womb, energy inside the earth
\end{abstract}

\section{Introduction}

Inside the earth there is a lot of energy is store in the form of heat. According to the law of conservation of energy "Energy can neither be created nor it is destroyed, however energy can be converted from one form energy to any other form of energy". Heat inside the earth is generated mainly by the decay of radioactive elements like thorium, uranium and potassium. The high-speed fragments of the broken nucleus heat the mantle by friction. Uranium emits high-energy alpha particles and their kinetic energy is degraded into heat.

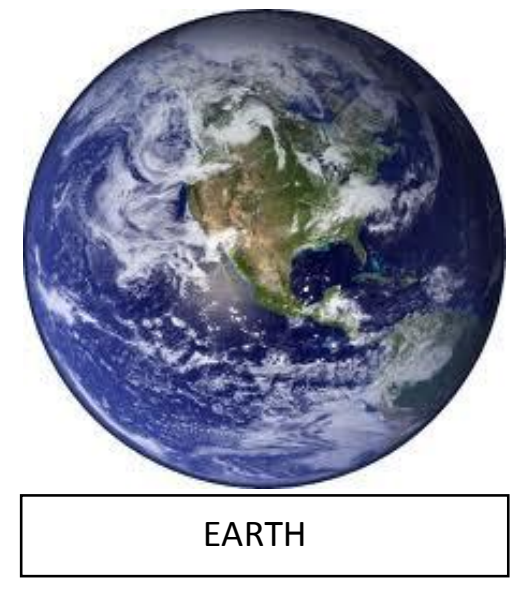

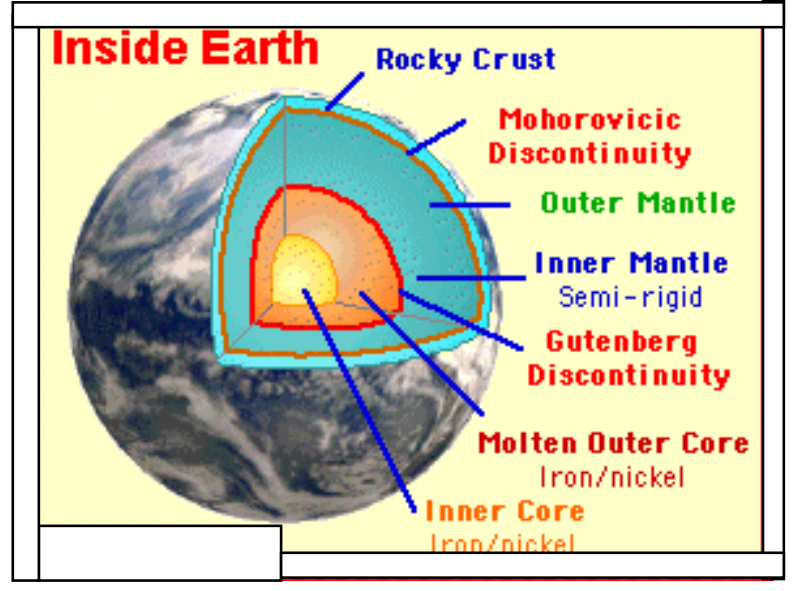

INSIDE THE EARTH

Earth is made of many different and distinct layers. Each layer having the uniqueness in their nature, deeper layers are composed of heavier materials; they are hotter, denser and under much greater pressure than the outer layers.

Earth layer consists of inner core, molten outer core, inner mantle, rocky crust, outer mantle.

Inner Core: The Earth has iron-nickel core that is about 2,100 miles in radius. The inner core may have a temperature up to about $13,000^{\circ} \mathrm{F}\left(7,200^{\circ} \mathrm{C}=7,500 \mathrm{~K}\right)$, which is hotter than the surface of the sun. The inner core (which has a radius of about 750 miles $(1,228 \mathrm{~km})$ is solid. The outer core is in a liquid state and is about 1,400 miles $(2,260 \mathrm{~km})$ thick.

molten outer core: molten outer core this exixts above the inner core and below the inner mantle The outer core of the Earth is a liquid layer about 2,266 km (1,408 mi) thick composed of iron and nickel which lies above the Earth's solid inner core and below its mantle. Its outer boundary lies 2,890 km (1,800 mi) beneath the Earth's surface. The transition between the inner core and outer core is located approximately $5,150 \mathrm{~km}(3,200 \mathrm{mi})$ beneath the Earth's surface.

Inner Mantle: interior of the Earth is chemically divided into layers. The mantle is a highly viscous layer between the crust and the outer core. Earth's mantle is a rocky shell about 2,900 km (1,800 mi) thick that 
constitutes about $84 \%$ of Earth's volume. It is predominantly solid and encloses the iron-rich hot core, which occupies about $15 \%$ of Earth's volume

Crust: - The crust is Earth's outermost layer, and it is the only layer that scientists can directly study. Earth's crust ranges from 8 to 70 kilometers (5 to 40 miles) thick, according to Michael Zeilik's Astronomy: The Evolving Universe (Cambridge, 2002). It is solid and has a rocky composition. The top portion of the crust is the only portion of Earth's interior that geologists can study directly. Under the crust is the rocky mantle, which is composed of silicon, oxygen, magnesium, iron, aluminum, and calcium. The upper mantle is rigid and is part of the lithosphere (together with the crust). The lower mantle flows slowly, at a rate of a few centimeters per year. The asthenosphere is a part of the upper mantle that exhibits plastic properties. It is located below the lithosphere (the crust and upper mantle), between about 100 and 250 kilometers deep.

Outer Mantle: The outer mantle is a lot thinner than the inner mantle. It can be found between 7 miles $(10 \mathrm{~km})$ and 190 miles $(300 \mathrm{~km})$ below the surface of the earth. You can divide the outer mantle into two different layers. The bottom layer is tough liquid rock and probably consists of silicates of iron and magnesium. The temperature in this part is between $2520^{\circ} \mathrm{F}\left(1400^{\circ} \mathrm{C}\right)$ and $5400^{\circ} \mathrm{F}\left(3000^{\circ} \mathrm{C}\right)$ and the density is between $3.4 \mathrm{~g} / \mathrm{cm}^{3}$ and $4.3 \mathrm{~g} / \mathrm{cm}^{3}$. The upper layer of the outer mantle consists of the same material but is stiffer because of its lower temperature.

\section{Procedure}

On sending two ways channeled non melted pipe with high pressure near to the inner core, on pumping cool water to the ground level near to inner core the naturally vapor comes out from other end of the pipe, On connecting reactor and turbines the generated heat will be stores and converts in the form of electricity by using generator.

\section{Extraction of electricity from earth's womb}

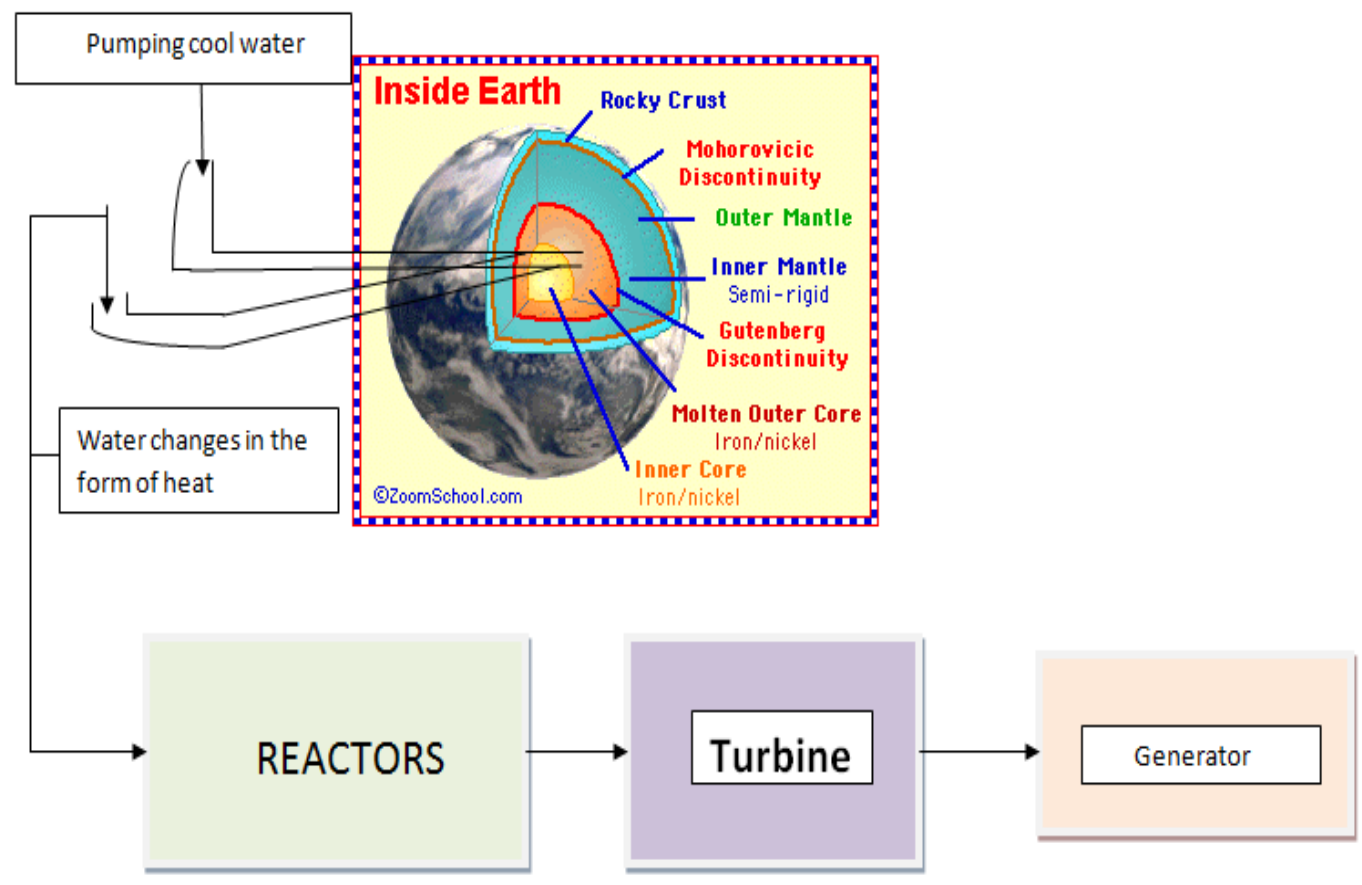

Reactor: The reactor core generates heat in number of ways

- The kinetic energy of fission products is converted to thermal energy when these nuclei collide with nearby atoms.

- Some of the gamma rays produced during fission are absorbed by the reactor, their energy being converted to heat.

- Heat is produced by the radioactive decay of fission products and materials that have been activated by neutron absorption. This decay heat source will remain for some time even after the reactor is shut down.

Turbines: - A turbine is a rotary mechanical device that extracts energy from a fluid flow and converts it into useful work. And these are stored into generators in the form of electricity 


\section{Acknowledgement}

I sincerely convey my thanks to my beloved Vice - chancellor \& our founder first Bishop YESHU DARBAR, Rev. Fr. Prof.(Dr.) Rajendra B. Lal for his guidance, support and help , and I also convey my thanks to my mother and grandmother Mrs.Swarnalatha.N \& M. Amulya Prema for their parental guidance.

\section{Conclusion}

By using this process of extracting electrical energy from earth we can reduce the fossil fuels consumption, on decrease of fossil fuels in atmosphere it will reduces the pollution, and this process of extracting electricity will synchronize the cost factor.

\section{References}

[1] $\square \wedge$ Paul Mann, Lisa Gahagan, and Mark B. Gordon, "Tectonic setting of the world's giant oil and gas fields," in Michel T. Halbouty (ed.) Giant Oil and Gas Fields of the Decade, 1990-1999, Tulsa, Okla.: American Association of Petroleum Geologists, p.50, accessed 22 June 2009.

[2] $\wedge$ Structure of the Earth. The Encyclopedia of Earth. March 3, 201

[3] Jeanloz, Raymond (2000). "Mantle of the Earth". In Haraldur Sigurdsson, Bruce Houghton, Hazel Rymer, John Stix, Steve McNutt. Encyclopedia of Volcanoes. San Diego: Academic Press. pp. 41-54. ISBN 978-0-12-643140-7. Retrieved 2010-05-17. 